\title{
Detection of human papillomavirus DNA and p53 codon 72 polymorphism in prostate carcinomas of patients from Argentina Gustavo J Leiros ${ }^{1}$, Silvia R Galliano1, Mario E Sember ${ }^{2}$, Tomas Kahn,4, Elisabeth Schwarz ${ }^{3}$ and Kumiko Eiguchi*1
}

\author{
Address: ${ }^{1}$ Catedra de Bioquimica e Inmunologia, Facultad de Medicina-Universidad del Salvador, Buenos Aires, Argentina, ${ }^{2}$ Servicio de patología, \\ Hospital Israelita, Buenos Aires, Argentina, ${ }^{3}$ Deutsches Krebsforschungszentrum, Heidelberg, Germany and ${ }^{4}$ Expert Team Life Sciences, Deutsche \\ Bank AG, Frankfurt, Germany \\ Email: Gustavo J Leiros - gustavoleiros@yahoo.com.ar; Silvia R Galliano - srgalliano@yahoo.com.ar; \\ Mario E Sember - eddysember@hotmail.com; Tomas Kahn - tomaskahn@web.de; Elisabeth Schwarz - e.schwarz@dkfz-heidelberg.de; \\ Kumiko Eiguchi* - keiguchi@uolsinectis.com.ar \\ * Corresponding author
}

Published: 24 November 2005

BMC Urology 2005, 5:15 doi:10.1/86/147I-2490-5-15
Received: 17 March 2005

Accepted: 24 November 2005

This article is available from: http://www.biomedcentral.com/147I-2490/5/15

(C) 2005 Leiros et al; licensee BioMed Central Ltd.

This is an Open Access article distributed under the terms of the Creative Commons Attribution License (http://creativecommons.org/licenses/by/2.0), which permits unrestricted use, distribution, and reproduction in any medium, provided the original work is properly cited.

\begin{abstract}
Background: Infections with high-risk human papillomaviruses (HPVs), causatively linked to cervical cancer, might also play a role in the development of prostate cancer. Furthermore, the polymorphism at codon 72 (encoding either arginine or proline) of the $p 53$ tumor-suppressor gene is discussed as a possible determinant for cancer risk. The HPVE6 oncoprotein induces degradation of the $\mathrm{p} 53$ protein. The aim of this study was to analyse prostate carcinomas and hyperplasias of patients from Argentina for the presence of HPV DNA and the $p 53$ codon 72 polymorphism genotype.
\end{abstract}

Methods: HPV DNA detection and typing were done by consensus $\mathrm{LI}$ and type-specific PCR assays, respectively, and Southern blot hybridizations. Genotyping of $p 53$ codon 72 polymorphism was performed both by allele specific primer PCRs and PCR-RFLP (Bsh 12361). Fischer's test with Woolf's approximation was used for statistical analysis.

Results: HPV DNA was detected in 17 out of 41 (4I.5 \%) carcinoma samples, whereas all 30 hyperplasia samples were HPV-negative. Differences in $p 53$ codon 72 allelic frequencies were not observed, neither between carcinomas and hyperplasias nor between HPV-positive and HPVnegative carcinomas.

Conclusion: These results indicate that the $p 53$ genotype is probably not a risk factor for prostate cancer, and that HPV infections could be associated with at least a subset of prostate carcinomas.

\section{Background}

Prostate cancer is one of the most common malignancies in males, but little is known about the molecular events involved in its development [1]. The prostate could constitute a target for infection with human papillomaviruses
$(H P V)$ due to anatomical reasons, particularly by direct access of the viral particles through the urethra. Penile and urethral HPV lesions have been described [2], as well as an increased prostate cancer risk associated with sexual behaviour [3]. Several studies have shown the presence of 
$H P V$ DNA in prostate carcinomas and hyperplasias $[4,5]$, whereas others could not detect any [6]. Thus, the possible role of $H P V$ in prostate carcinogenesis is still unclear.

The carcinogenic potential of high risk HPV types (such as HPV16 and HPV18) is largely determined by the two oncoproteins E6 and E7. A major function of E6 is to bind and to target the tumor-suppressor protein p53 for proteosomal degradation [7], whereas E7 inactivates the retinoblastoma protein $\mathrm{pRb}$ [8]. There exists a polymorphic sequence in the $p 53$ gene at codon position 72 encoding either arginine (Arg) or proline (Pro) [9]. It has been reported that the p53 protein with Arg (p53-Arg72) is more susceptible to E6-mediated degradation than the proline form (p53-Pro72) and that the Arg allele is overrepresented in cervical cancer patients [10]. The conclusion that the $p 53$-Arg72 allele confers a higher risk for cervical cancer development than the p53-Pro72 allele has either been supported by subsequent studies [11] or not [12]. On the other hand, it has been shown that Pro homozygosity is associated with a reduced risk of prostate cancer [13], and therefore this allele could have some protective effect.

In this study we have analyzed prostate neoplasia samples of patients from Buenos Aires, Argentina, in order to evaluate the prevalence of HPV DNA and the distribution of p53 codon 72 alleles. We have tried to minimize the possibility of urethral HPV contaminations by using microdissection for further sample processing before DNA extraction.

\section{Methods \\ Studied Population}

89 caucasian men older than 60 years were studied from whom 41 had prostate adenocarcinoma diagnosis and the 48 remaining had hyperplasia diagnosis. All patients were from Buenos Aires city, Argentina.

Helsinki recommendations for tissue sampling were observed. In addition, we had scientific committee approvals from institutions involved in the present report.

\section{Clinical samples}

Samples of histopathologically confirmed adenocarcinomas and benign hyperplasias were obtained by biopsy (transrectal prostatic puncture method). Three to five specimens (puncture biopsy) were obtained from each patient, fixed in formaldehyde-phosphate buffer, embedded in paraffin, and slides from these pieces were stained with hematoxylin-eosin for histopathological analysis. Blood samples from each patient were also obtained by venous puncture and collected in tubes with EDTA.

\section{Dissection of neoplastic tissue}

Specimens with hyperplasias or infiltrated by adenocarcinoma cells were first selected. In a second selection process the areas corresponding to carcinoma or hyperplasia were microdissected in order to obtain samples with the highest percentage of neoplastic cells. Slides and hematoxylin-eosin staining from these new fragments were performed to confirm the success of the procedure. These steps were repeated as many times as necessary to obtain

Table I: Oligonucleotides used as primers and radiolabelled probes for HPV type-specific and consensus PCR.

\begin{tabular}{|c|c|c|}
\hline Oligonucleotide & Nucleotide sequence & Localization in HPV genome \\
\hline TS-HPV6-I & +5'-TAGTGGGCCTATGGCTCGTC-3' & E5: $4671-4690$ \\
\hline TS-HPV6-2 & -5'-TCCATTAGCCTCCACGGGTG-3' & $E 5: 4931-4950$ \\
\hline TS-HPV6 probe & +5'-CATTAACGCAGGGGCGCCTGAAATTGTGCC-3' & $E 5: 476 I-4790$ \\
\hline TS-HPVII-I & +5'-GGAATACATGCGCCATGTGG-3' & $L I: 684 I-6860$ \\
\hline TS-HPVII-2 & $-5^{\prime}-$ CGAGCAGACGTCCGTCCTCG-3' & $L I: 7 \mid 8 I-7200$ \\
\hline TS-HPVII probe & +5'-CGCCTCCACCAAATGGTACACTGGAGGATA-3' & $L I: 6977-7006$ \\
\hline TS-HPVI6-I & +5'-TGCTAGTGCTTATGCAGCAA-3' & $L I: 6028-6047$ \\
\hline TS-HPVI6-2 & -5'-ATTTACTGCAACATTGGTAC-3' & $L I: 6160-6179$ \\
\hline TS-HPVI6 probe & +5'-CAAACCACCTATAGGGGAACACTGGGGCA-3' & $L I: 6117-6146$ \\
\hline TS-HPVI8-I & +5'-AAGGATGCTGCACCGGCTGA-3' & $L I: 6903-6922$ \\
\hline TS-HPVI8-2 & $-5^{\prime}-$-CACGCACACGCTTGGCAGGT-3' & $L I: 7100-7119$ \\
\hline TS-HPVI8 probe & +5'-TGGTTCAGGCTGGATTGCGTCGCAAGCCCA-3' & $L I: 7021-7050$ \\
\hline MYII & $+5^{\prime}-$ GCMCAGGGWCATAAYAATGG-3' $(\mathrm{W}=\mathrm{A}+\mathrm{T}, \mathrm{Y}=\mathrm{C}+\mathrm{T} ; \mathrm{M}=\mathrm{A}+\mathrm{C})$ & $L I: 6582-6601$ \\
\hline MY09 & $-5^{\prime}-$ CGTCCMARRGGAWACTGATC-3' $(\mathrm{W}=\mathrm{A}+\mathrm{T} ; \mathrm{R}=\mathrm{A}+\mathrm{G} ; \mathrm{M}=\mathrm{A}+\mathrm{C})$ & $L I: 7033-70 \mid 4$ \\
\hline \multicolumn{3}{|l|}{ Consensus probe: } \\
\hline MYI8 & +5'-CTGTTGTTGATACTACACGCAGTAC-3' & LI \\
\hline MY46 & +5'-CTGTGGTAGATACCACWCGCAGTAC-3' & LI \\
\hline MY57 & +5'-CTGTGGTAGATACCACACGTAGTA-3' & LI \\
\hline WDI47 & +5'-CTGTAGTGGACACTACCCGCAGTAC-3' & LI \\
\hline
\end{tabular}


Table 2: PCR primers used for the analysis of $p 53$ polymorphism at codon 72 .

\begin{tabular}{llll}
\hline Allele & Primer & Primer sequence & PCR product size \\
\hline$p 53-P r o 72$ & $p 53$ Pro + & 5'GCCAGAGGCTGCTCCCCC3' & 178 bp \\
& $p 53-$ & 5'CGTGCAAGTCACAGACTT3' & \\
\hline p53-Arg72 & $p 53+$ & 5'TCCCCCTTGCCGTCCCAA3' & 136 bp \\
& $p 53$ Arg- & 5'CTGGTGCAGGGGCCACGC3' & \\
\hline
\end{tabular}

microscopic images showing more than $90 \%$ of neoplastic cells.

\section{DNA extraction}

Genomic DNA from deparaffinized tumor samples and peripheral blood cells was obtained by proteinase K digestion, followed by phenol-chloroform extraction and ethanol precipitation. To assess the quality of the isolated DNA for PCR, a 268 bp long segment of the $\beta$-globin gene was amplified by PCR using the primers GH20 and PC04. Only DNA samples showing specific amplification with this set of primers were used for HPV- and/or p53-specific PCR assays. Due to the small sizes of many biopsies and the low amounts of DNA extracted, it was not possible to perform both HPV and p53 PCR experiments with all samples.

\section{Detection and typing of HPV DNA by PCR and hybridization}

DNA samples of all 41 prostate carcinomas and of 30 prostate hyperplasias were available for HPV analysis. DNA of the 18 remaining hyperplasia samples was completely used up for the p53 PCR analysis. As described in Hoffmann et al. [14], DNA was first analyzed for the presence of HPV sequences by multiplex PCR with type-specific (TS) primers for HPV types 6, 11, 16 and 18 (Table 1). TS-PCR-negative samples and samples for which only very small amounts of DNA were available were subjected to PCR with the consensus L1 primers MY09 and MY11, able to recognize a wide range of mucosotropic HPV types (Table 1). PCR reactions were performed in a Peltier Thermal Cycler 2000 DNA Engine (MJ Research Inc., Watertown, Massachusetts, USA). The reaction conditions for TS-PCR were as follows: initial denaturation at $94^{\circ} \mathrm{C}$ for 5 minutes, 39 cycles with denaturation at $94^{\circ} \mathrm{C}$ for 1 minute, annealing at $54^{\circ} \mathrm{C}$ for 2 minutes and elongation at $72^{\circ} \mathrm{C}$ for 2 minutes. In the last cycle, the elongation step was extended to 10 minutes. The reaction conditions for PCR amplification with the consensus primers were identical, with the exception that annealing was performed at $55^{\circ} \mathrm{C}$ for 1 minute. In each PCR reaction we took precautions to an extreme in order to avoid contaminations with PCR products. For this purpose we manipulated both reagents and products in completely separated rooms, and used disposable materials and different sets of instruments. Furthermore, a negative control (water instead of DNA) was included in each set of PCR reactions.

For each experiment, $150 \mathrm{ng}$ of DNA from the patient sample was used together with 50 pmoles of each primer, $0.01 \mu$ moles of each dNTP, $1.5 \mathrm{mM}$ of $\mathrm{MgCl}_{2}$ and 2 units of Taq DNA polymerase in reaction buffer (GIBCO BRLLife Technologies Inc Gaithersburg, MD, USA). HPV-positive and negative control reactions were done in parallel in all experiments. In the HPV type-specific PCR assays, the $H P V$-positive controls included genomic DNA of SiHa (HPV16-positive cell line), and C4-I (HPV18-positive cell line), as well as cloned DNA of HPV6 and HPV11. In the consensus L1 PCR, genomic SiHa DNA was used as HPVpositive control. In both types of PCR assays, DNA from the HPV-negative cell line HaCaT was used as HPV-negative control. PCR products were subjected to electrophoresis on $2 \%$ agarose minigels, visualized by ethidium bromide staining and blotted on Type $\mathrm{B}$ positive nylon membranes (Fluka Chemie AG, Buchs, Switzerland). Southern hybridization was performed with the radiolabelled oligonucleotide probes shown in Table 1. Filter

Table 3: HPV DNA in prostate carcinomas and hyperplasias.

\begin{tabular}{|c|c|c|c|c|c|}
\hline \multirow[t]{2}{*}{ Samples } & \multicolumn{4}{|c|}{ HPV+ } & \multirow[t]{2}{*}{ HPV- } \\
\hline & HPV I6 & HPV II & HPV Consensus ${ }^{a}$ & $H P V+$ total & \\
\hline Prostate carcinomas $(n=4 I)$ & $5^{b}$ & 2 & 10 & $17^{c}$ & 24 \\
\hline Prostate hyperplasias $(n=30)$ & 0 & 0 & 0 & 0 & 30 \\
\hline
\end{tabular}

a samples were negative in the TS-PCR, but HPV-positive in the MY09/MYII PCR.. ${ }^{b} p=0.068$, Fischer's Exact Test with Woolf's approximation; ${ }^{c} p$

$<0.000$ I, Fischer's Exact Test with Woolf's approximation. 


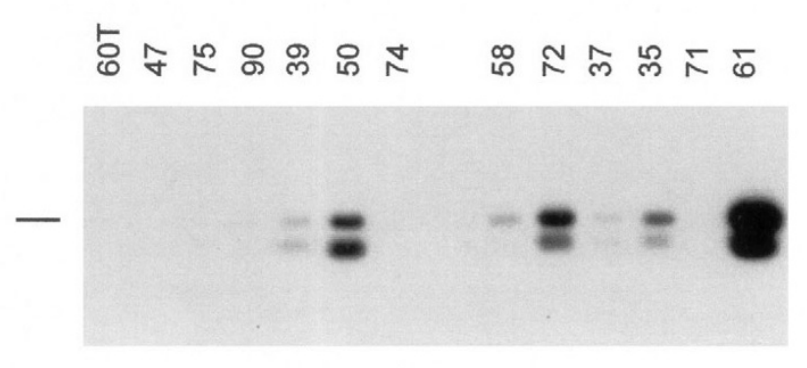

\section{Figure I}

HPV DNA detection in prostate carcinomas. PCR reactions using primers MY09 and MYII were performed. After gel electrophoresis and transfer, the filter was hybridized with consensus probes. Positive $(\mathrm{SiHa})$ and negative ( $\mathrm{HaCaT}$, water) controls were included in the experiment, but are not shown in the figure. The numbers above the lanes indicate the designation of the carcinoma samples. The bar on the left side indicates the position of the MY09/I I PCR product of approximately 450 bp length. Two hybridization signals are visible in the HPV-positive samples. The upper band corresponds to the MY09/II PCR product. The additional lower band which was also seen in other experiments using these batches of the MY09/I I primers, appeared exclusively as a companion of the HPV-specific 450 bp product. We did not try to clarify the nature of this extra-band.

hybridization, washing, and exposure as well as 5'-end labelling of oligonucleotide probes were done as described [14].

\section{PCR assays for p53 polymorphism at codon 72}

PCR was performed as described in Storey et al. [10] with tumor and peripheral blood cell DNA. For the p53 PCR, DNA of 39 prostate carcinomas (the DNA of 2 samples was completely used up for the HPV-specific PCR assays) and 48 prostate hyperplasias was available. Two sets of primer pairs (Table 2) were used for detection of p53Pro72 and p53-Arg72 sequences, respectively. The different variants could be discriminated by the different sizes of PCR products (Table 2). The PCR conditions were as follows for the p53-Pro72 allele: denaturation at $94^{\circ} \mathrm{C}$ for 5 minutes, then 35 cycles with denaturation at $94^{\circ} \mathrm{C}$ for 1 minute, annealing at $56^{\circ} \mathrm{C}$ for 1 minutes and elongation at $72^{\circ} \mathrm{C}$ for 1 minute. In the last cycle, the elongation step was extended to 10 minutes. For the p53-Arg72 allele, the PCR conditions were identical with the exception that annealing was performed at $62^{\circ} \mathrm{C}$ for 1 minute. The PCR products were separated in $3 \%$ agarose gels. Possible assay outcomes were: 1) if a PCR product (136 bp) was obtained only with the arginine-specific primers, the patient was considered arginine homozygous, 2) if only a proline-specific primer product (178 bp) was obtained, the patient was considered proline homozygous, 3) if the
Table 4: Genotypes and frequencies of codon 72 p53 polymorphism variants in prostate carcinomas and hyperplasias.

\begin{tabular}{lll}
\hline p53 codon 72 allele & $\begin{array}{l}\text { Prostate } \\
\text { Carcinomas }\end{array}$ & $\begin{array}{l}\text { Prostate } \\
\text { Hyperplasias }\end{array}$ \\
\hline Arg/Arg & $20(0.51)$ & $23(0.48)$ \\
Pro/Pro & $2(0.05)$ & $2(0.04)$ \\
Pro/Arg & $17(0.44)$ & $23(0.48)$ \\
Total & 39 & 48 \\
\hline
\end{tabular}

The data are a summary of all experiments because identical results were obtained for each DNA with the two methods used for p53 allele typing (allele specific PCR, and PCR-RFLP), and no differences were observed between the two DNA sample sources (peripherical blood leucocytes or neoplastic tissue) from the individual patients.

sample showed amplification with both two primer sets, the patient was considered heterozygous (Arg/Pro).

A second assay for $p 53$ polymorphism status was performed using a RFLP (restriction fragment length polymorphism) site for the enzyme Bsh1236I (5'-CGCG-3'), present in the Arg allele (CGC-G), but not in the Pro allele (CCC-G) [9]. PCR reactions were performed with the $p 53^{+}$ and $p 53$ - external primers (table 2), using $p 53$-Pro72 allele PCR conditions, amplifying a product of 279 bp length. The PCR product was then digested with $10 \mathrm{U}$ of Bsh1236I (Fermentas GmbH, St. Leon-Rot, Germany) during 90 minutes at $37^{\circ} \mathrm{C}$. Digestion products were run in $3 \%$ agarose gels. In case of the Arg allele, cleavage products of $160 \mathrm{bp}$ and $119 \mathrm{bp}$ were obtained.

\section{Statistical analysis}

Statistical analysis was performed using exact Fisher's test with Woolf's approximation. Statistical analysis was performed with Statistica 5.0 software program (Stat Soft Inc Tulsa, OK, USA).

\section{Results}

\section{Presence of HPV DNA in prostate tissues}

To assess the presence of HPV DNA in prostate lesions, DNA of histopathologically confirmed samples of 41 prostate carcinomas and 30 prostate hyperplasias was analyzed. The tumor sections were obtained by microdissection in order to minimize contamination with stromal tissue. Using multiplex PCR and Southern blot for HPV types 6, 11, 16 and 18, five HPV16-positive and 2 HPV11positive prostate carcinomas were detected, whereas all benign prostate hyperplasias were negative (Table 3 ). The HPV-negative samples were subjected subsequently to PCR with the MY09/MY11 consensus primers and Southern blot with consensus probes (Figure 1). This assay detected 10 additional HPV-positive carcinoma samples, whereas all benign hyperplasias remained negative (Table 3). Unfortunately, no HPV typing could be performed 

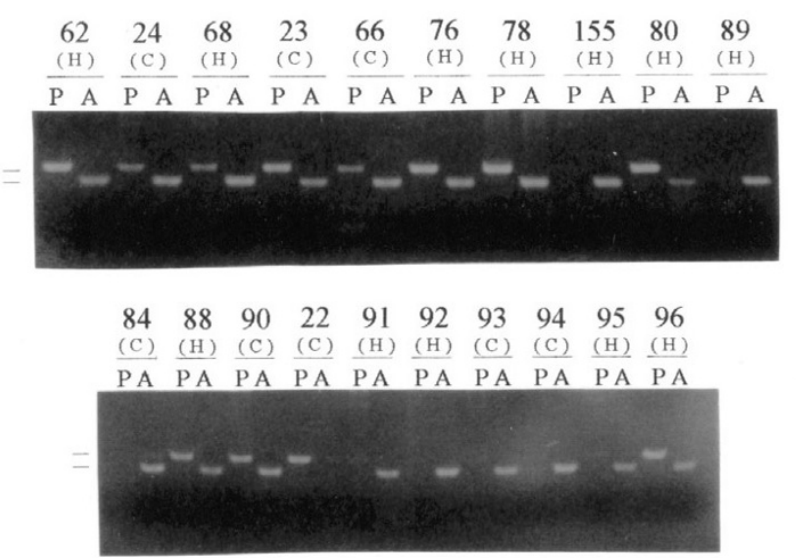

Figure 2

Analysis of $p 53$ codon 72 polymorphism in prostate carcinomas and hyperplasias by allele-specific PCR. The PCR products were run on a $3 \%$ agarose gel. Numbers above the lanes indicate the designation of the tumor samples. $(\mathrm{H})$ and $(\mathrm{C})$ denote prostate hyperplasia or carcinoma, respectively. A or $\mathrm{P}$ indicate the use of Arg or Pro specific primer sets, respectively. The bars on the left side indicate the positions of the PCR products for Arg allele (I $36 \mathrm{bp}$ ) and Pro allele (I 78 bp).

with the MY09/MY11-positive samples mainly due to the lack of additional DNA material. Statistical analysis indicated a significant association (Fischer's exact test with Woolf's approximation, $\mathrm{p}<0.0001$ ) between HPV DNA presence and prostate carcinomas.

\section{p53 polymorphism at codon 72}

In parallel to the HPV studies, we have analyzed the p53 polymorphism at codon 72 (Arg, Pro or Arg/Pro) in the leukocyte and tumor DNA from 39 patients with prostate carcinomas and 48 patients with prostate hyperplasias by allele-specific PCR and PCR-RFLP analysis. The results of the allele-specific PCR are shown in Figure 2. The two methods gave consistent results for each DNA, and no differences were detected between the tumor and normal DNA of each patient. The data are summarized in Table 4. Among the 39 prostate cancer patients, 20 Arg homozygotes, 2 Pro homozygotes, and 17 Arg/Pro heterozygotes were identified. From the hyperplasia patients, 23 were Arg homozygotes, 2 Pro homozygotes, and the 23 remaining heterozygotes. For the statistical analysis, the p53 Pro allele-carrying patients (Pro homozygotes and Arg/Pro heterozygotes) were grouped together and compared with the Arg homozygotes, in order to evaluate the latter genotype as risk factor. In the frequency of p53 Arg homozygosity no significant differences (Fischer's exact test with Woolf's approximation, $\mathrm{p}=0.831$ ) could be detected between carcinoma and hyperplasia patients.
Table 5: Genotypes and frequencies of codon 72 p53 polymorphism variants in HPV-positive and HPV-negative prostate carcinomas

\begin{tabular}{lll}
\hline p53 codon 72 allele & \multicolumn{2}{c}{ Prostate Carcinomas } \\
\cline { 2 - 3 } & HPV (+) & HPV (-) \\
\hline Arg/Arg & $9(0.53)$ & $11(0.50)$ \\
Pro/Pro & $2(0.12)$ & $0(0)$ \\
Pro/Arg & $6(0.35)$ & $11(0.50)$ \\
Total & 17 & $\mathbf{2 2}$ \\
\hline
\end{tabular}

Next, we compared the $p 53$ codon 72 allelic frequencies between patients with $H P V$-positive and $H P V$-negative carcinomas in order to evaluate whether an association between $p 53$ Arg homozygosity and HPV-positivity might exist. From 17 patients with $H P V$-positive carcinomas, 9 were Arg homozygotes, 2 were Pro homozygotes and 6 were Arg/Pro heterozygotes. From the 22 patients with $H P V$-negative carcinomas, 11 were Arg homozygotes, none were Pro homozygotes and 11 were heterozygotes (Table 5). For the Fisher's test the samples were grouped in the same way as described above. No significant differences (Fischer's exact test with Woolf's approximation, $\mathrm{p}$ $=1.00$ ) in the frequency of $p 53$ Arg homozygosity could be observed between $H P V$-positive and HPV-negative prostate carcinomas.

\section{Discussion}

In the analysed sample collection we have detected a great difference in $H P V$ positivity between prostate carcinomas ( 17 out of $41=41,5 \%$ ) and hyperplasias ( 0 out of $30=0$ \%) From the 7 carcinomas with identified HPV type, 5 samples contained the high-risk HPV16 and 2 samples the low-risk HPV11. The presence of HPV16 DNA supports the assumption that high-risk $H P V$ infections are associated with at least a subset of prostate cancers. The presence of HPV11 DNA points to the possibility that HPV can infect the prostate, but these infections have probably no influence on the carcinogenic process.

After more than 10 years of HPV DNA analysis in benign and malignant prostate samples, the causal involvement of HPV in prostate carcinogenesis is still a matter of controversial debate. The discrepant results and methodological problems of the earlier analyses have already been discussed in Cuzick [5] and Strickler et al [6]. It has been speculated that the discrepancies could be due to HPV contamination from nearby tissues during the sampling procedure since HPV DNA has been detected in urethral $[15,16]$ and anal $[17,18]$ tissues. Based on these data some authors recommended radical prostatectomy as tis- 
sue source, as well as an exhaustive microdissection of the neoplastic sample. For the present study radical prostatectomy samples could not be obtained. However, we have performed a microdissection approach to exclude contaminating anal tissue as well as to minimize stromal content from the samples. On the other hand, if a HPV contamination from anal epithelium is a common event during biopsy taking and sample manipulation, it would be expected that both carcinomas and hyperplasias show some degree of HPV detection. However, we could not detect any HPV DNA in the hyperplasias. In some recent studies, HPV DNA was either detected in prostate cancer samples [19] or not [20,21]. Possible explanations for the divergent frequencies of $H P V$-positivity in prostate cancer samples may be found in populational, geographical, environmental and genetic heterogeneities, beyond methodological detection problems.

In cervical cancer, several studies of the $p 53$ codon 72 polymorphism have been performed after the initial report claiming a higher cancer risk associated with the Arg allele [10]. Some of them refute the original finding [22-24] whereas others support it $[25,26]$. In our analysis of the p53 polymorphism at codon 72 , we could not find an indication that the Arg allele confers a higher risk for prostate cancer, including those tissues positive for HPV. The use of two different typing methods and polymorphism determination, in both blood and tumor samples, avoid misinterpretations due to methodological typing problems and $\mathrm{LOH}$ in cancer samples. A recent study came to the conclusion that the Pro/Pro genotype is associated with a reduced risk of prostate cancer [13]. We could not evaluate this hypothesis due to the extremely low populational frequency of the rare Pro/Pro genotype.

It will remain important issues for future studies of prostate carcinogenesis to assess the presence, expression and potential role of $H P V$ and to further understand the contribution of $p 53$ mutations and polymorphisms.

\section{Conclusion}

In the present work, HPV DNA was detected in 17 out of $41(41,5 \%)$ prostate cancer samples, whereas all 30 tested benign hyperplasias were $H P V$-negative. The results allow the conclusion that HPV infections might be associated with prostate carcinoma development, at least in a subset of cases. In addition, the allelic frequencies of the p53 codon 72 polymorphism (Arg, Pro or Arg/Pro) were determined in the patients with benign and malignant tumors in order to evaluate the possibility of increased cancer susceptibility associated with the Arg allele. However, no statistically significant differences in the Arg and Pro (Pro plus Arg/Pro) allelic frequencies could be detected, neither by comparing patients with carcinomas and hyper- plasias nor between $H P V$-positive and $H P V$-negative carcinomas.

\section{Competing interests}

(1) The authors declare that they have no competing interests.

(2) Financial resources expended during the assays were supported by PICT0528 Grant from National Agency for Scientific and Technology Promotion (Argentina), ARG 99/029 mobility Grant from the International Bureau of the Federal Ministry of Education, Science, Research and Technology (BMBF, Germany) and the Secretary for Technology, Science and Productive Innovation (SETCIP, Argentina), and Alberto J Roemmers Foundation Grant.

\section{Authors' contributions}

GJL carried out the molecular genetic studies, performed the statistical analysis and drafted the manuscript. SRG carried out the pathological diagnosis and microdissected the biopsy samples. MES carried out the prostatic biopsies and contributed with clinical urologic knowledge. TK participated in the design of the study. ES participated in the design of the study, gave continuous technical support and helped to draft the manuscript. KE planned the study, and participated in its design and coordination. All authors read and approved the final manuscript.

\section{Acknowledgements}

We wish to thank Claudia Lohrey, Steffen Hollmer, Inés Stella, Carolina Sofer Podestá, and Romina Montani for expert technical assistance. This work was supported in part by mobility grant ARG 99/029 from the International Bureau of the Bundesministerium für Bildung und Forschung (BMBF, Germany) and the Secretaría para la Tecnología, la Ciencia, y la Innovación Productiva (SETCIP, Argentina) and Alberto J Roemmers Foundation.

\section{References}

I. Ruijter E, van de Kaa C, Miller G, Ruiter D, Debruyne F, Schalken J: Molecular genetics and epidemiology of prostate carcinoma. Endocr Rev 1999, 20:22-45.

2. zur Hausen H: Papillomaviruses causing cancer: Evasion from host cell control in early events in carcinogenesis. J Natl Cancer Inst 2000, 92:690-698.

3. Key T: Risk factors for prostate cancer. Cancer Surv 1995, 23:63-77.

4. Moyret-Lalle C, Marcais C, Jacquemier J, Moles JP, Daver A, Soret JY, Jeanteur P, Ozturk M, Theillet C: Ras, p53 and HPV status in benign and malignant prostate tumors. Int J Cancer 1995, 64:124-129.

5. Cuzick J: Human papillomavirus infection of the prostate. Cancer Surv 1995, 23:91-95.

6. Strickler HD, Burk R, Shah K, Viscidi R, Jakcson A, Pizza G, Bertoni F, Schiller JT, Manns A, Metcalf R, Qu W, Goedert JJ: A multifaceted study of human papillomavirus and prostate carcinoma. Cancer 1998, 82: | | |8-।| 25.

7. Thomas M, Pim D, Banks L: The role of the E6-p53 interaction in the molecular pathogenesis of HPV. Oncogene 1999, 18:7690-7700.

8. Münger K, Basile JR, Duensing S, Eichten A, Gonzalez SL, Grace M, Zacny VL: Biological activities and molecular targets of the human papillomavirus E7 oncoprotein. Oncogene 200I, 20:7888-7898. 
9. Matlashewski G], Tuck S, Pim D, Lamb P, Schneider J, Crawford LV: Primary structure polymorphism at amino acid residue 72 of human p53. Mol Cell Biol 1987, 7:961-963.

10. Storey A, Thomas M, Kalita A, Harwwod C, Gardiol D, Mantovani F, Brever J, Leight IM, Matlashewski G, Banks L: Role of $p 53$ polymorphism in the development of human papillomavirus-associated cancer. Nature 1998, 393:229-234.

II. Zehbe I, Voglino G, Wilander E, Delius H, Marongiu A, Edler L, Klimek F, Andersson S, Tomamasino M: P53 codon 72 polymorphism and various human papillomavirus 16 E6 genotypes are risk factors for cervical cancer development. Cancer Res 200I, 61:608-611.

12. Malcolm EK, Baber GB, Boyd JC, Stoler MH: Polymorphism at codon 72 of $p 53$ is not associated with cervical cancer risk. Mod Pathol 2000, 13:373-378.

13. Henner WD, Evans AJ, Hough KM, Harris EL, Lowe BA, Beer TM: Association of codon $\mathbf{7 2}$ polymorphism of $p 53$ with lower prostate cancer risk. Prostate 200I, 49:263-266.

14. Hoffmann M, Kahn T, Mahnke CG, Goeroegh T, Lippert BM, Werner JA: Prevalence of human papillomavirus in squamous cell carcinoma of the head and neck determined by polymerase chain reaction and southern blot hybridization: Proposal for optimized diagnostic requirements. Acta Otolaryngol (Stockh) 1998, I 18:138-144.

15. Grussendorf-Conen E, Deutz FJ, de Villiers EM: Detection of human papillomavirus-6 in primary carcinoma of the urethra in men. Cancer 1987, 60:1832-1835.

16. Mevorach RA, Cos LR, di Sant Agnese PA, Stoler M: Human papillomavirus type 6 in grade I transitional cell carcinoma of the urethra. J Urol 1990, 143:126-128.

17. Scholefield JH, Hickson WG, Smith JH, Rogers K, Sharp F: Anal intraepithelial neoplasia: part of a multifocal disease process. Lancet 1992, 340: I27I-I273.

18. Beckmann AM, Daling JR, Sherman KJ, Maden C, Miller BA, Coates RJ, Kiviat NB, Myerson D, Weiss NS, Hislop TG: Human papilomavirus infection and anal cancer. Int J Cancer 1989, 43: 1042-1049.

19. Serth J, Panitz F, Paeslack U, Kuczyk MA, Jonas U: Increased levels of human papillomavirus type 16 DNA in a subset of prostate cancers. Cancer Res 1999, 59:823-825.

20. Noda T, Sasagawa T, Dong Y, Fuse H, Namiki M, Inoue M: Detection of human papillomavirus (HPV) DNA in archival specimens of benign prostatic hyperplasia and prostatic cancer using a highly sensitive nested PCR method. Urol Res 1998, 26: 165-169.

21. Saad F, Gu K, Jean-Baptiste J, Gauthier J, Mesmasson AM: Absence of human papillomavirus sequences in early stage prostate cancer. Can J Urol 1999, 6:834-838.

22. Rosenthal A, Ryan A, Al-Jehani RM, Storey A, Harwood CA, Jacobs IJ: p53 codon 72 polymorphism and risk of cervical cancer in UK. Lancet 1998, 352:87|-872.

23. Josefsson A, Magnusson PK, Ylitalo N, Magnusson P, Ylitalo N, Quarforth-Tubbin P, Ponten J, Adami H, Gyllensten U: p53 polymorphism and risk of cervical cancer. Nature 1998, 396:53I-532.

24. Giannoudis A, Graham DA, Southern SA, Herrington CS: P53 codon $72 \mathrm{Arg} / \mathrm{Pro}$ polymorphism is not related to HPV type or lesion grade in low- and high- grade squamous intra-epithelial lesions and invasive squamous carcinoma of the cervix. Int J Cancer 1999, 83:66-69.

25. Zehbe I, Voglino G, Wilander E, Genta F, Tommasino M: Codon $\mathbf{7 2}$ polymorphism of $p 53$ and its association with cervical cancer. Lancet 1999, 354:218-219.

26. Szarka K, Veress G, Juhasz A, Konya J, Sapy T, Soos G, Hernadi Z Gergely L: Integration status of virus DNA and p53 codon 72 polymorphism in human papillomavirus type 16 positive cervical cancers. Anticancer Res 2000, 20:2161-2167.

\section{Pre-publication history}

The pre-publication history for this paper can be accessed here:

http://www.biomedcentral.com/1471-2490/5/15/prepub
Publish with Bio Med Central and every scientist can read your work free of charge

"BioMed Central will be the most significant development for disseminating the results of biomedical research in our lifetime. "

Sir Paul Nurse, Cancer Research UK

Your research papers will be:

- available free of charge to the entire biomedical community

- peer reviewed and published immediately upon acceptance

- cited in PubMed and archived on PubMed Central

- yours - you keep the copyright

Submit your manuscript here:

http://www.biomedcentral.com/info/publishing_adv.asp
BioMedcentral 